\title{
Martensite formation in Fe-C alloys at cryogenic temperatures
}

Villa, Matteo; Hansen, Mikkel Fougt; Somers, Marcel A. J.

\section{Published in:}

Scripta Materialia

Link to article, DOI:

10.1016/j.scriptamat.2017.08.005

Publication date:

2017

Document Version

Peer reviewed version

Link back to DTU Orbit

Citation (APA):

Villa, M., Hansen, M. F., \& Somers, M. A. J. (2017). Martensite formation in Fe-C alloys at cryogenic temperatures. Scripta Materialia, 141, 129-132. https://doi.org/10.1016/j.scriptamat.2017.08.005

\section{General rights}

Copyright and moral rights for the publications made accessible in the public portal are retained by the authors and/or other copyright owners and it is a condition of accessing publications that users recognise and abide by the legal requirements associated with these rights.

- Users may download and print one copy of any publication from the public portal for the purpose of private study or research.

- You may not further distribute the material or use it for any profit-making activity or commercial gain

- You may freely distribute the URL identifying the publication in the public portal

If you believe that this document breaches copyright please contact us providing details, and we will remove access to the work immediately and investigate your claim 


\title{
Martensite formation in Fe-C alloys at cryogenic
}

\section{temperatures}

M. Villa, ${ }^{1, *}$ M.F. Hansen, ${ }^{2}$ M.A.J. Somers ${ }^{1}$

${ }^{1}$ Department of Mechanical Engineering, Technical University of Denmark, DK-2800 Kongens Lyngby, Denmark

${ }^{2}$ Department of Micro- and Nanotechnology, DTU Nanotech, Building 345B, Technical University of Denmark, DK-2800 Kongens Lyngby, Denmark

* corresponding author; Tel: +45 45252221; Fax: 45251961

\begin{abstract}
Magnetometry was applied to quantify the fraction of austenite retained in Fe-C alloys subjected to various treatments. These treatments consisted of: (i) water quenching; (ii) water quenching followed by immersion in boiling nitrogen and again in water; (iii) as for (ii) but re-heating from $77 \mathrm{~K}$ at a rate of $0.0083 \mathrm{~K} \mathrm{~s}^{-1}$; (iv) as for (iii) but (re-)heating at $0.167 \mathrm{~K} \mathrm{~s}^{-1}$ interrupted by an isothermal step. Data was coupled with hardness measurements and demonstrates that the re-heating conditions from $77 \mathrm{~K}$ significantly influence the fraction of austenite retained at the end of the thermal cycle.
\end{abstract}

Keywords: martensitic phase transformation; steel; cryogenic treatment 
In 1925, Mathews [1] suggested as the first that cooling carbon steel to sub-zero Celsius temperatures after conventional cooling to room temperature could promote additional formation of martensite, yielding a reduction of the fraction of retained austenite and consequently attaining an increase in hardness. These concepts were further established over the next two decades [2-5].

The austenite-to-martensite transformation at sub-zero Celsius temperatures in carbon steel was systematically investigated in the 1940s by Cohen et al. [5]. According to Cohen, martensite formation in steel progresses during cooling to approx. $120 \mathrm{~K}$ and further cooling would be ineffective. Moreover, the transformation halts on interrupting the cooling and does not proceed during re-heating. The work of Cohen implies that cooling carbon steel down to at least $120 \mathrm{~K}$ minimizes the fraction of retained austenite.

Conversely, several investigators showed that, when $\mathrm{Fe}-\mathrm{C}$ alloys are cooled fast to cryogenic temperatures (i.e. $<120 \mathrm{~K}$ ), an austenite-to-martensite transformation can manifest during re-heating of the material [6-8]. Martensite formation during re-heating takes place in the temperature interval $90-170 \mathrm{~K}$ and indicates that the austenite-tomartensite transformation is time-dependent at sub-zero Celsius temperatures. Thus, if the transformation is, at least partly, suppressed by fast cooling, it can take place on subsequent re-heating.

So far, it has not been clarified to which extent the heating rate influences the fraction of austenite retained in carbon steel upon cryogenic treatment, and consequently whether the heating rate from $77 \mathrm{~K}$ influences hardness and possibly other properties and performance of components. Indications in this direction were only recently reported in Ref. [9]. 
In the present work, three Fe-C alloys were synthesized by induction melting from elemental $\mathrm{Fe}(99.9999 \%$ pure) and graphite. The C content of the alloys was measured after casting by combustion analysis and amounted (in wt- $\%$ ) to $0.97 \pm 0.01$, $1.20 \pm 0.02$ and $1.59 \pm 0.02$. Disc-shaped samples were with a thickness of $0.7 \mathrm{~mm}$ and a diameter of $3 \mathrm{~mm}$ machined from an as-cast $4 \mathrm{~mm}$ diameter rod.

After machining, samples were homogenized at $1380 \mathrm{~K}$ for $64.8 \mathrm{ks}$ in continuous Ar flow, austenitized at $1350 \mathrm{~K}$ for $180 \mathrm{~s}$, water quenched and tempered at $950 \mathrm{~K}$ for $0.6 \mathrm{ks}$. Subsequently, each sample was austenitized at $1350 \mathrm{~K}$ for $180 \mathrm{~s}$ and water quenched. After water quenching, some of the samples were cryo-treated. Storage time at room temperature prior to cryo-treatment was approx. $0.5 \mathrm{ks}$. Two types of cryotreatments were applied: (i) immersion in boiling nitrogen followed by immersion in water (up-quenching); (ii) immersion in boiling nitrogen followed by isochronal heating at $0.00833 \mathrm{~K} \mathrm{~s}^{-1}\left(0.5 \mathrm{~K} \mathrm{~min}^{-1}\right)$.

The Fe-1.2\%C alloy was selected for a series of additional experiments. The microstructure of the material was subjected to a second austenitization and tempering cycle. Prior to cryo-treatment, the material was austenitized and stored as reported above. Slight decarburization of the samples was revealed by an approx. $1 \%$ lower fraction of retained austenite after water quenching as compared to the first set of experiments. Cryo-treatment consisted of immersion in boiling nitrogen followed by reheating to room temperature: (i) at a constant rate of $0.167 \mathrm{~K} \mathrm{~s}^{-1}\left(10 \mathrm{~K} \mathrm{~min}^{-1}\right)$; (ii) at a constant rate of $0.167 \mathrm{~K} \mathrm{~s}^{-1}$ interrupted for $7.5 \mathrm{ks}$ by an isothermal stage at selected temperatures; (iii) at a constant rate of $0.167 \mathrm{~K} \mathrm{~s}^{-1}$ interrupted by an isothermal step at $130 \mathrm{~K}$ for $60.5 \mathrm{ks}$. 
The austenite-to-martensite transformation was followed in situ by magnetometry. Magnetometry was performed with a LakeShore Cryotronics 7407 vibrating sample magnetometer equipped with a 74018 low-temperature option. A magnetic field of 1 Tesla was applied to bring the samples to magnetic saturation. Details of the experimental set-up are given elsewhere [10].

The (molar) fraction of austenite in the samples, $f_{\alpha^{\prime}}$, was quantified according to:

$$
f_{\gamma}=1-f_{\alpha^{\prime}}=1-\frac{\sigma}{\sigma_{\alpha^{\prime}}}
$$

where $\sigma$ is the measured specific magnetization (magnetic moment per mass) at saturation of the sample, and $\sigma_{\alpha^{\prime}}$ is the magnetization at saturation of pure iron (i.e. $217.6 \mathrm{emu} / \mathrm{g}$ [11]) multiplied by the weight percentage of Fe atoms in the material. Eq. 1 is based on the assumption that the magnetization of austenite is negligible (see also Ref. [12]). In fact, the magnetization of austenite under applied magnetic field of 1 Tesla is typically $<1 \mathrm{emu} / \mathrm{g}$.

Hardness measurements were performed approx. 10 months after heat treatment on the most representative sample for each condition using a Future Tech model FM700 micro-hardness tester equipped with a Vickers indenter applying a load of $0.5 \mathrm{~kg}$ and a dwell time of $10 \mathrm{~s}$.

The results of the first series of experiments are presented in Figs. 1 and 2 and compared to the available literature data.

First of all, Figs. 1 and 2 show that data obtained in the present investigation are in good agreement with literature data. Fig. 1 reveals that retained austenite is present in all investigated alloys for all conditions. The fraction of retained austenite increases 
with increasing $\mathrm{C}$ content for all investigated conditions. Moreover, for all alloys investigated in the present work, the fraction of retained austenite is largest in the samples conventionally cooled to room temperature and lowest in the samples additionally immersed in boiling nitrogen and isochronously re-heated to room temperature at a slow rate.

Fig. 2 illustrates that the hardness of conventionally treated Fe-C alloys are comparable for the $0.97 \% \mathrm{C}$ and the $1.2 \% \mathrm{C}$ alloys, whereas hardness is significantly lower for the $1.59 \% \mathrm{C}$ alloy. Immersion in boiling nitrogen increases hardness and the increment is most pronounced for the $1.59 \% \mathrm{C}$ alloy. Among the cryo-treated samples, maximum hardness is observed for a $\mathrm{C}$ content of $1.2 \%$. Additionally, for the three investigated alloys the hardness is maximized upon slow heating of the material from 77 $\mathrm{K}$. The increase in hardness promoted by slow controlled heating at $0.00833 \mathrm{Ks}^{-1}$ as compared to immersion of the material in water is approx. 30, 35 and $45 \mathrm{HV}$ for $0.97 \% \mathrm{C}, 1.2 \% \mathrm{C}$ and $1.59 \% \mathrm{C}$, respectively.

Evidently, data consistently indicate that immersion in boiling nitrogen promotes martensite formation in addition to conventional cooling to room temperature. Furthermore, data unequivocally demonstrates that the heating rate applied during heating from $77 \mathrm{~K}$ to room temperature affects the martensite content in $\mathrm{Fe}-\mathrm{C}$ alloys: slow heating promotes an additional transformation of retained austenite into martensite as compared to up-quenching in water.

Data of the interrupted heating from boiling nitrogen temperature to room temperature are presented in Fig. 3 as the fraction of retained austenite converted into martensite, $-\Delta f_{\gamma}$, versus temperature, $T$. 
Fig. 3 shows that during continuous heating at $0.167 \mathrm{~K} \mathrm{~s}^{-1}$ (dashed black line) the austenite-to-martensite transformation starts at approx. $90 \mathrm{~K}$ and continues to approx. $220 \mathrm{~K}$. If the heating is interrupted for an isothermal stage, the transformation continues isothermally at all the chosen intermediate temperatures (i.e. $100 \mathrm{~K}, 130 \mathrm{~K}$, $160 \mathrm{~K}$ and $190 \mathrm{~K}$ ) and proceeds fastest at $130 \mathrm{~K}$. After the isothermal stage, heating at $0.167 \mathrm{~K} \mathrm{~s}^{-1}$ is re-established and the transformation continues up to approx. $220 \mathrm{~K}$ as for the un-interrupted heating cycle.

Upon reaching room temperature, the effect of a $7.5 \mathrm{ks}$ isothermal stage during heating from $77 \mathrm{~K}$ on the fraction of retained austenite is relatively small for the investigated cycles, despite large differences in the fraction transformed in the respective isothermal stages.

Conversely, an isothermal stage prolonged to $60.5 \mathrm{ks}$ as applied for $130 \mathrm{~K}$, where the transformation rate is fastest, has a noticeable effect on the additionally transformed fraction of austenite. During the more than $16 \mathrm{~h}$ isothermal interruption at $130 \mathrm{~K}$ a significant fraction of retained austenite transforms isothermally into martensite. This fraction is larger than the fraction that would have transformed during continuous heating to room temperature at the applied heating rate. Resuming heating after the isothermal stage leads to additional transformation of austenite. At the end of the cycle, $f_{\gamma}$ is $2.3 \pm 0.3 \%$ and the hardness amounts to $996 \mathrm{HV}$, which are the minimum austenite fraction and the maximum hardness value achieved. ${ }^{1}$

${ }^{1}$ A direct comparison with data in Figs. $1 \mathrm{~b}$ and 2 is not possible due to slight decarburization of the samples. However, the fraction of retained austenite in these samples is lower than for $0.97 \% \mathrm{C}$ samples heated at a rate of $0.0083 \mathrm{~K} \mathrm{~s}^{-1}$, strongly supporting the observation that long isothermal holding at cryogenic temperatures maximizes the conversion of austenite into martensite. 
Evidently, by applying a long isothermal holding step at cryogenic temperatures it is possible to further reduce the fraction of retained austenite in carbon steel compared to current practice. Conversely, short isothermal treatments are not as effective. Consequently, it is not surprising that long isothermal holding steps at cryogenic temperature have been reported to have a significant impact on the performance of carbon steel components in service. [33-35]

The observations in the present work can be understood by considering timedependent martensite formation. Shih et al. [36] were the first to present experimental data on isothermal martensite formation in ferrous (Fe-Ni-Mn) alloys at sub-zero Celsius temperature. Their well-known result shows C-curves just as in ordinary TTT diagrams applied for diffusion controlled transformation of austenite at high temperature. Here it is demonstrated that similar C-curves for sub-zero Celsius martensite formation provide a consistent interpretation of the present results on $\mathrm{Fe}-\mathrm{C}$ alloys.

A schematic sub-zero Celsius TTT diagram is shown by the drawn lines denoted $\Delta f_{i}$ (the additional fraction of austenite transformed into martensite) in Fig. 4a. The horizontal dashed line denoted $M_{S}^{i s o}$ represents the temperature below which a driving force builds up for isothermal martensite formation [37]. The dash-dot lines represent schematic heating curves. Firstly, from the intersections of the heating curves with the transformation curves it follows that the heating rate should have an influence on the fraction of martensite that has formed on reaching room temperature. This is observed for the three investigated Fe-C alloys: slow heating at $0.00833 \mathrm{Ks}^{-1}$ led to a lower fraction of retained austenite and associated higher hardness on reaching RT (Figs. 1b and 2) as compared to up-quenching in water. Secondly, Fig. 4 a indicates that 
interruption of martensite formation during continuous heating, results into continued transformation. Thirdly, the fraction of martensite that has developed shifts to higher temperature with increasing heating rate.

Actually, the drawn lines in Fig. 4a only apply for isothermal transformation and, analogous to continuous cooling transformation (CCT) diagrams, where the transformation lines are shifted to a lower temperature, the transformation lines for a continuous heating transformation (CHT) diagram will be shifted to higher temperature. Fig. $4 \mathrm{~b}$ shows experimental data obtained for Fe- $1.2 \mathrm{wt}-\% \mathrm{C}$ at various heating rates and connects points of equal (additionally) transformed fraction of martensite. Indeed, the heating rate influences the fraction transformed.

Based on the present investigation, it is suggested that cryogenic treatment as an intermediate step in the hardening of Carbon steels can be further optimized by tailoring the temperature program considering sub-zero Celsius TTT and CHT diagrams.

Summarizing, the present work shows that martensite formation in $\mathrm{Fe}-\mathrm{C}$ alloys during sub-zero Celsius treatment is partly time-dependent. The experimental observations of a reduction of the fraction of retained austenite content (and associated increase in hardness) for low heating rates from $77 \mathrm{~K}$ as compared to up-quenching in water as well as intermittent isothermal stages as compared to continuous heating conditions can be consistently interpreted in terms of sub-zero Celsius TTT and continuous heating transformation (CHT) diagrams. 
This work was financially supported by the Danish Council for Independent Research [G.R. grant: DFF-4005-00223]. E.J. Mittemeijer, Max Planck Institute for intelligent systems, Stuttgart, DE, is acknowledged for supplying the $\mathrm{Fe}-\mathrm{C}$ alloys.

\section{References}

[1] J.A. Mathews, Trans. AIME 71 (1925) 568-596.

[2] A. P. Gulyaev, Vestn. Inzh. Tekh. 4-5 (1946) 140-147.

[3] E. Szewandin, M. Mironczik. J. Tech. Phys., 7, 2275 (1937)

[4] J. Mazur, Nature 165.4198 (1950) 610-611

[5] M. Cohen, Trans. ASM 41 (1949) 35-94.

[6] G.V. Kurdjumov, O.P. Maksimova, Dokl Akad Nauk SSSR, 61.1 (1948) 83-86.

[7] L. Cheng, C.M. Brakman, B. M., Korevaar, E.J. Mittemeijer, Metall. Trans. 19A.10 (1988) 2415-2426.

[8] A. Stojko, M.F. Hansen, J. Slycke, M.A.J. Somers, A S T M International. Journal, 8.4 (2011) JAI103459

[9] M. Villa, T. Christiansen, M.F. Hansen, M.A.J. Somers, Metall. Ita., 11:12 (2015) $39-46$.

[10] M. Villa, "Isothermal martensite formation", $\mathrm{PhD}$ dissertation, 2014 Technical University of Denmark, Kgs Lyngby, Denmark.

[11] J. Crangle, G.M. Goodman, Proc. Rol. Soc. Lond., A321 (1971) 477-491.

[12] T. Fukuda, T. Kakeshita, K. Kindo, Mater. Sci. Eng. A 438-440 (2006) 212-217.

[13] H. Esser, W. Bungardt, Archiv Für Das Eisenhüttenwesen 7.10 (1934) 585-586.

[14] M. Mikami, Sci. Reports Tohoku University 23.3 (1934) 212-241.

[15] B.L. Averabach, L.S. Castleman, M. Cohen, Trans. ASM 42 (1950) 112-120. 
[16] C.S. Roberts, J. of Metals S 5.2 (1953) 203-204.

[17] D.P. Koistinen, R.E. Marburger, Acta Metall. 7.1 (1959) 59-60.

[18] A.R. Marder, G. Krauss, Trans. ASM 60.4 (1967): 651-660.

[19] V.G. Gavriljuk, S.A. Firstov, V.A. Sirosh, A.I. Tyshchenko, G.S. Mogilny, Metallofizika I Noveishie Tekhnologii, 38.4 (2016) 455-475.

[20] D.E. Kaputkin, Mater. Sci. Eng. A 438 (2006): 207-211.

[21] S.V. Grachev, O.V. Zhuikov, V.P. Gvozdovskii, E.S. Matsneva, D.I. Vichuzhanin, Metal Sci. Heat Treat., 53.1-2 (2011) 57-60

[22] M.G. Mendiratta, G. Krauss, Metall. Trans. A 3.7 (1972) 1755-1760.

[23] P.M. Kelly, J. Nutting, Proc. R. Soc. A-math. Phys. Eng. Sci 259.1296 (1960) 4558.

[24] D. A. Mirzayev, M.M. Shteynberg, T. N. Ponomareva, V.M. Schastlivtsev, Phys. Met. Metallogr. 47.1 (1979) 102-111.

[25] G. Krauss, Mater. Sci. Eng. A 273 (1999) 40-57.

[26] G.R. Speich, H. Warlimont, J. Iron Steel Inst. 206 (1968) 385-392.

[27] J.M. Hodge, M.A. Orehoski, Trans. AIME 167 (1946) 627-642.

[28] J.M. Chilton, P.M. Kelly, Acta Metall. 16.5 (1968) 637-656.

[29] J.L. Burns, T.L. Moore, R.S. Archer. Trans. AIME 26 (1938), S. 1-36.

[30] Tamaru, Sci. Papers of the Inst. of Phys. and Chem. Research 67 (1926) 25-44.

[31] Litwinchuk, F.X. Kayser, H.H. Baker, A. Henkin, J. Mater. Sci. 11.7 (1976) 12001206.

[32] ASTM Designation: E140 - 12b (2012) DOI: 10.1520/E0140-12B

[33] R.F. Barron, Tappi J. 57.5 (1974): 137-139.

[34] R.F. Barron, Cryogenics, 1 (1982): 409-413 
[35] K. Moore, D.N. Collins, Key Eng. Mater. 86-87 (1993) 47-54

[36] C.H. Shih, B. L. Averbach, M. Cohen, J. of Metals 7:1 (1955) 183-187.

[37] J.C. Zhao, M.R. Notis, Mater. Sci. Eng. R, 15:4-5 (1995) 135-207. 


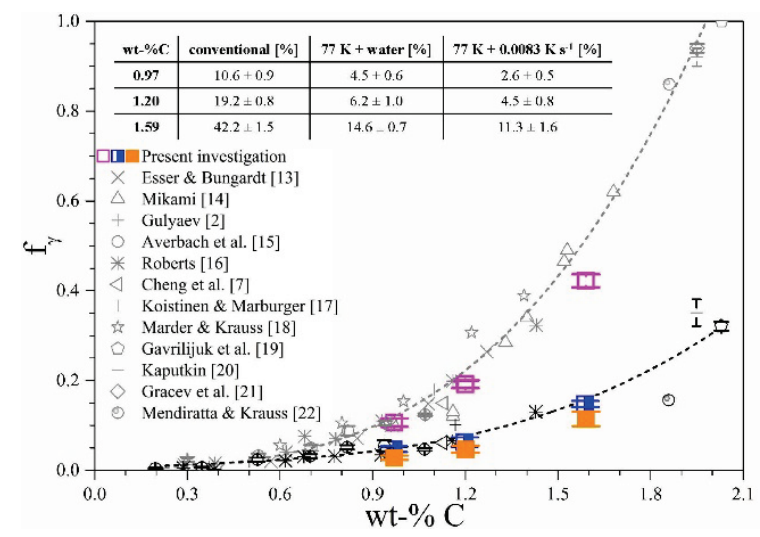

Figure 1. Fraction of retained austenite $f_{\gamma}$ plotted versus carbon content. Data relative to the present investigation are reported as follows: magenta, open symbols refer to samples cooled to room temperature; blue, half-filled symbols to samples additionally immersed in boiling nitrogen and water; orange, full symbols to samples additionally immersed in boiling nitrogen and re-heated at a rate equal to $0.00833 \mathrm{Ks}^{-1}$. Data refer to the average of a minimum of 6 measurements. Error bars indicate the standard deviation of measurements. Literature data are: grey for conventional treatment to room temperature; black for additionally cooling to cryogenic temperatures (i.e. $\mathrm{T}<130 \mathrm{~K}$ ). 


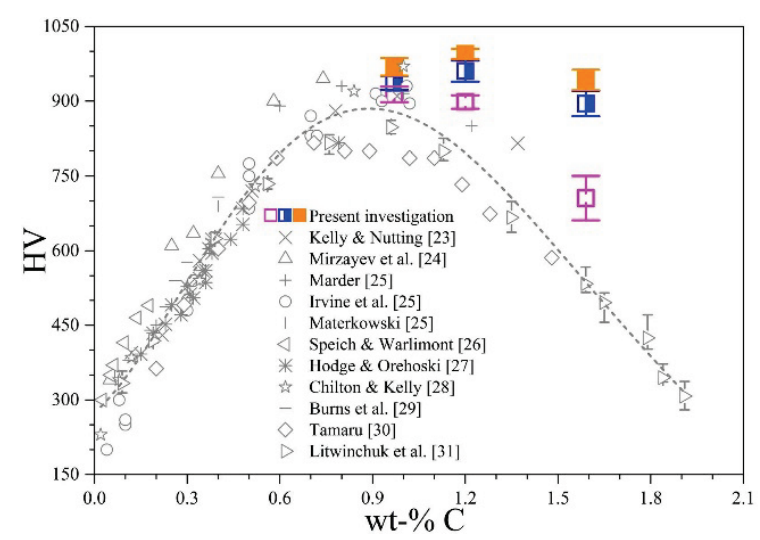

Figure 2. Vickers hardness of (martensitic) carbon steel, HV, plotted versus carbon content. Data relative to the present investigation are reported consistently with Fig. 1. Data refer to the average of a minimum of 15 measurements. Error bars indicate the standard deviation of measurements. Literature data refer to carbon steel conventionally cooled to room temperature. When necessary, conversion from Rockwell C to Vickers hardness was based on ASTM Designation: E140 - 12b [32]. Data points from Ref. [24] refer to martensite formed at plateau III (see Ref. [24]). Data points from Kurdjumov in Ref. [25] were excluded based on Ref. [26]. For Ref. [28], only data relative to bulk specimens were considered. 


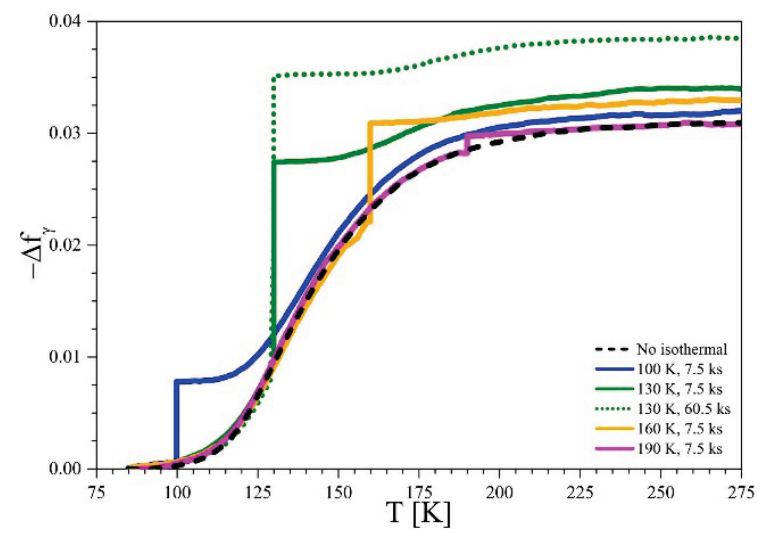

Figure 3. Fraction of retained austenite transformed into martensite during re-heating from $77 \mathrm{~K}$. Data refer to averaged values of a minimum of two runs. The total fraction transformed during heating was reproducible within $\pm 0.2 \%$. 

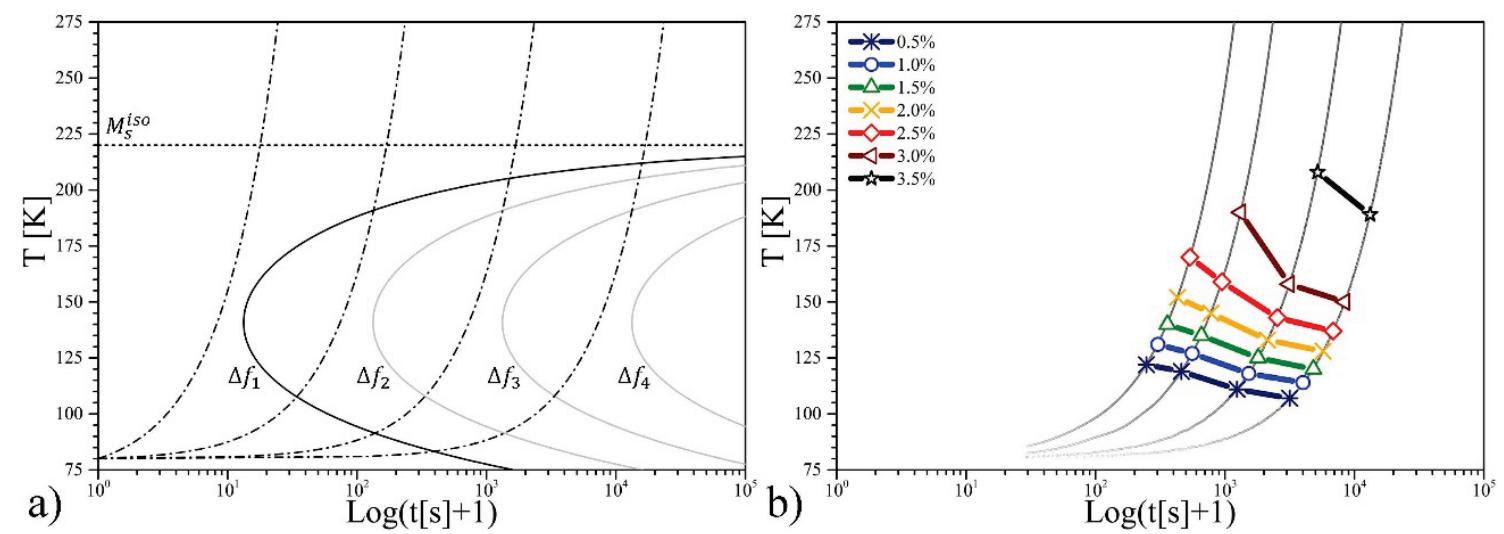

Figure 4. a) TTT diagram at sub-zero Celsius temperature for additionally formed austenite fraction, $\Delta f_{i}$. The drawn lines represent constant fraction of formed martensite during isothermal treatment; the dash-dot lines represent continuous heating curves at different rates, demonstrating that up-queching can prevent additional martensite formation and that the different martensite contents achieved on reaching a temperature above $\mathrm{M}_{\mathrm{S}}^{\mathrm{iso}}$ depends on the heating rate. Also, heating interrupted by an isothermal stage, i.e. by interconnecting two dash-dot lines at a constant temperature (not shown), leads to additional martensite formation. b) Continuous Heating Transformation (CHT) diagram for Fe-1.2 C, showing different heating rates and interconnecting additionally transformed fractions: slower heating leads to lower austenite fraction and higher final hardness. Applied heating rates were $0.0083 \mathrm{~K} \mathrm{~s}^{-1}, 0.025 \mathrm{~K} \mathrm{~s}^{-1}, 0.083 \mathrm{~K} \mathrm{~s}^{-1}$ and $0.167 \mathrm{~K}$ $\mathrm{S}^{-1}$. 